\title{
Fixed ratio punishment of free operant avoidance responding
}

T. A. MCCULLOUGH, CHARLES J. SHUMAN, and ROGER W. MCINTIRE University of Maryland, College Park, Md. 20742

Free-operant-avoidance responding of six female hooded rats was suppressed by response-contingent shocks presented according to fixed-ratio schedules. The degree of response-rate suppression and shock-rate acceleration was a function of the punishment ratio.

The effect of superimposing a punishment contingency upon bar pressing maintained by avoidance schedules has been shown to be related to the intensity of the punishment shocks in both Marmosets (Sandler et al, 1966b) and rats (Powell \& Morris, 1969). The effects of frequency of punishment have not been well documented. Low-ratio schedules of punishment are known to produce substantial decrements in the response rate and avoidance efficiency of rats (McIntire et al, 1968; Powell \& Morris, 1969). Sandler et al (1966a) seem to have made the only parametric manipulation of the punishment ratio. They reported that high avoidance efficiency was maintained in spite of an added punishment contingency of several, sequentially applied, ratio values. They do not suggest a differential effect of the ratio value.

The absence of a clear demonstration of systematic effects of the value of the punishment ratio is surprising since this variable is clearly important in the suppression of responding maintained by appetitive schedules (Azrin et al, 1963). The present experiment was designed to demonstrate such a differential effect of the punishment ratio on the response rate and avoidance efficiency of individual rats. It was expected that examining a greater range of ratio values than heretofore used, and recovering the avoidance baseline between administrations of the different punishment ratios, would facilitate the demonstration of these effects.

\section{SUBJECTS}

Six female Long-Evans rats were used. These rats were 100 days old at the start of the experiment and had no previous experimental history. Food and water were freely available in the home cages. \section{APPARATUS}

A Scientific Prototype rat chamber (Model A-100, without food cup) was fitted with a Lehigh Valley retractable lever (Model 1405, operated by $7 \mathrm{~g}$ of pressure) The chamber was located in a topless, sound-attenuating box within a larger room, and illuminated by a $100-\mathrm{W}$ light $6 \mathrm{ft}$ above the chamber. White noise was continually present. Shocks were generated and scrambled by a Grason-Stadler constant-current shock apparatus (Model E1064GS) and administered through the grid floor, two metal walls, and lever in the chamber. Responses (press of the lever) were recorded on digital counters.

\section{PROCEDURE}

All sessions were $30 \mathrm{~min}$ long and on consecutive days. On the day following adaptation to the chamber, Ss were trained

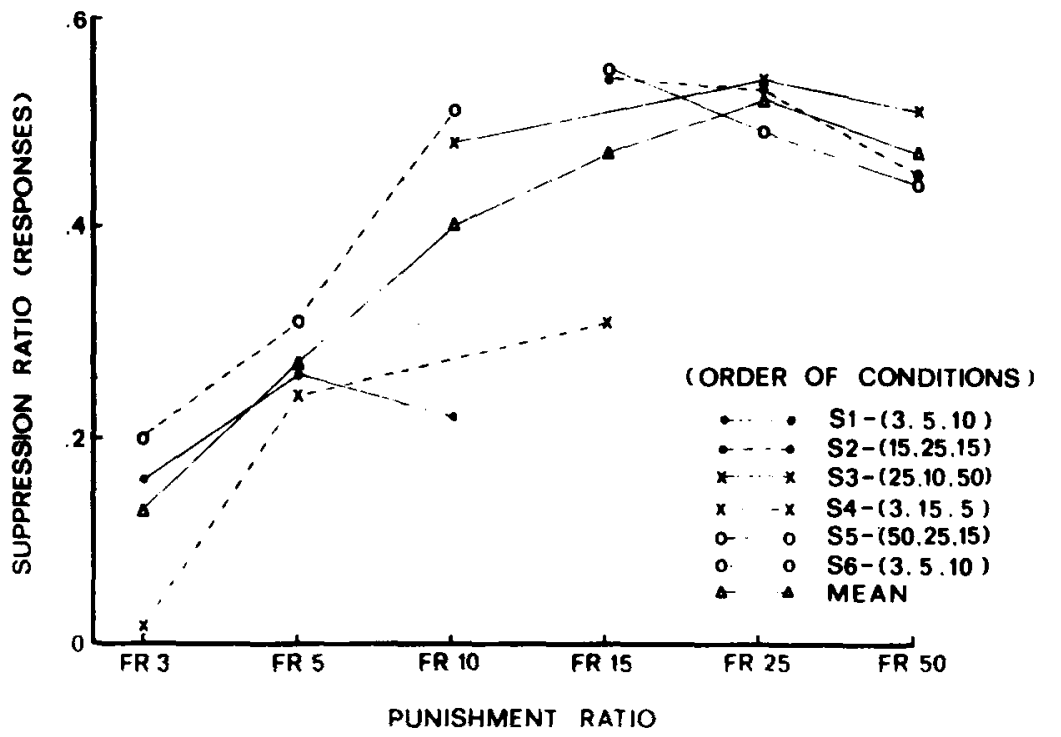

to bar press by an escape procedure in which $1.0 \mathrm{~mA}$ shocks occurred every $10 \mathrm{sec}$ in the absence of a response and continued until terminated by a response. Additional responses noncumulatively postponed the next shock onset by $10 \mathrm{sec}$ (cf. Boren et al, 1959).

On all following sessions, occurrence of shock $(1.0 \mathrm{~mA}, 0.5 \mathrm{sec})$ was governed by a Sidman avoidance schedule (Sidman, 1953) with shock-shock (S-S) and response-shock (R-S) parameters of 5 and $10 \mathrm{sec}$, respectively. Training on this schedule continued for 23 days. Across the last five sessions, number of shocks per session did not vary more than $10 \%$. Response rate was more variable, but in no case did the difference across these five sessions exceed $20 \%$.

Each $S$ was then exposed for 10 sessions to each of three values of a fixed ratio(FR) punishment schedule. Ten sessions of avoidance training without punishment were given between each block of sessions at a given $F R$ value. The FR values and orders for individual rats are shown in the figures. All punishment shocks were of the same intensity and duration as the shocks occurring according to the avoidance schedule which remained in effect.

\section{RESULTS}

A suppression ratio for responses was calculated by dividing the total number of responses made during the last five sessions in a given punishment condition by the number of responses made during both the last five baseline sessions preceding that punishment condition and the last five sessions of the punishment condition. Such a ratio may vary from 0.0 to 1.0 . A value of 0.5 indicates no suppression, and a value of 0.0 indicates complete suppression. A similar measure was calculated for avoidance shocks, but since in avoidance situations the shock rate is generally related inversely to response rate, the obtained values were subtracted from 1.0. This measure is better considered an acceleration ratio. Thus, values below 0.5 indicate an acceleration in the rate at which avoidance-scheduled shocks were received, relative to the baseline rate. Values near 0.5 indicate no change in shock rate, and values above 0.5 indicate a reduction in the shock rate.

Response rate suppression ratios for individual rats and for the set of three rats receiving a given punishment ratio condition are shown in Fig. 1. Lower ratios tended to produce greater suppression. This is evident both in the group data and in the individual data. Higher values produced only slight

Fig. 1. Response-rate suppression ratios for individual Ss and groups as a function of the punishment ratio. 


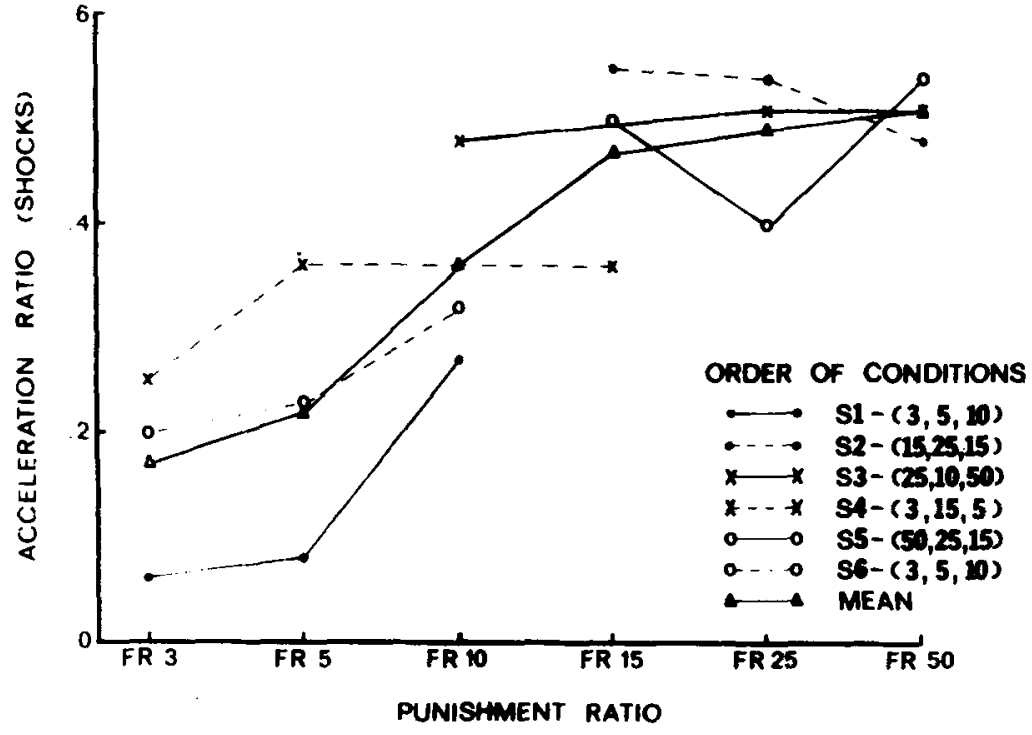

suppression. The data suggest that rats initially exposed to low ratios will show more suppression at higher ratios than will rats initially exposed to the higher ratios.

The effects on shock rate (Fig. 2) parallel those on response rate. FR values which produced response rate suppression also produced shock rate acceleration. This indicates that the effect of the punishment shocks was not to merely increase the efficiency of responding. Although there was a tendency for decreases in response rate to be greater than increases in shock rate, there are a few instances where substantial increases in shock rate are found without any noticeable decrease in response rate. This reflects a shift to a less efficient pattern of responding.

\section{DISCUSSION}

Punishment of avoidance results in an avoidance schedule in which the S.S parameter is kept constant while the R-S parameter at times becomes zero. Under such conditions, responding serves to increase the shock density of the situation. It is not surprising that responses subsequently become less probable or that the decrease in response probability is related to the degree to which responses increase shock density.

The responses which do not occur (i.e., are "suppressed" by the punishment contingency) are not randomly distributed. Both McIntire et al (1968) and Sandler et al (1966b) found that responses tended to occur in bursts following a shock. Such responses are commonly attributed to the escape training implicit or explicit in the early avoidance training and to a resultant eliciting property of the shock. Bursting, however, is inefficient, and in a ratio punishment situation, results in maximum increase in shock density. This suggests that if the change in shock density effected by the punishment contingency were the only controlling factor, bursting should be eliminated rather than maintained or enhanced. One factor which might account for the maintenance of bursting is the use of short S-S intervals and long R-S intervals. While bursting is inefficient relative to evenly spaced responding at the same overall rate, a response during the $S-S$ interval produces a greater and more immediate reduction in shock density than a response in the R-S interval.

This type of approach makes it clear that a meaningful statement of the effects of
CARL CHENEY and ROBERT CROW, Utah State University, Logan, Utah 84321

Light- and dark-reared rats received ablations of the superior colliculus, striate cortex, or both areas, and were later tested on a visual cliff. No significant difference in side preference was recorded between groups. Significantly more "no-descents" were recorded for the group undergoing the combined lesions, despite the use of a
Fig. 2. Shock-rate acceleration ratios for individual Ss and groups as a function of the punishment ratio.

punishment on avoidance responding requires parametric examination of avoidance schedule parámeters as well as punishment schedules parameters.

\section{REFERENCES}

AZRIN, N. H., HOLZ, W. C. \& HAKE, D. F Fixed-ratio punishment. Joumal of the Experimental Analysis of Behavior, 1963, 6, 141-148.

BOREN, J. J., SIDMAN, M., \& HERRNSTEIN, R. J. Avoidance, escape, and "extinction as functions of shock intensity. Journal of Comparative \& Physiological Psychology, 1959, $52,420-425$.

MCINTIRE, R. W., DAVIS, H., COHEN, S. I., \& FRANCH, E. O. Sidman avoidance performance under punishment and non-contingent shock conditions. Psychological Reports, 1968, 22, 897-903.

POWELL, R. W., \& MORRIS, G. Continuous punishment of free-operant avoidance in the rat. Journal of the Experimental Analysis of Behavior, 1969, 12, 149-157.

SANDLER, J., DAVIDSON, R, S., \& HOLZSCHUH, R. D. Effects of increasing punishment frequency on Sidman avoidance behavior. Psychonomic Science, 1966a, 5, 103-104.

SANDLER, J., DAVIDSON, R. S., GREENE, W. E., \& HOLZSCHUH, R. D. Effects of punishment intensity on instrumental avoidance behavior. Journal of Comparative \& Physiological Psychology, 1966b, 61, 212-216. SIDMAN, M. Avoidance conditioning with brief shock and no exteroceptive warning signal. Science, 1953, 118, 157-158.

\section{Lesion effects on visual cliff performance in the rat $^{1}$}

centerboard capable of inducing descents in the other Ss.

Depth discrimination, as indicated by visual-cliff performance, is present in many organisms at birth or within a short time the reafter (Walk \& Gibson, 1961). Behavioral studies have indicated both innate and learned components to visual discrimination (e.g., Gibson \& Walk, 1960), but little direct investigation has aimed at 